\title{
The influence of the accessibility of concentrate on the behaviour of cows milked in an automatic milking system
}

\author{
C.C. KETELAAR-DE LAUWERE ${ }^{1, *}$, A.H. IPEMA ${ }^{1}$, J.H.M. METZ ${ }^{1}$, \\ J.P.T.M. NOORDHUIZEN ${ }^{2}$ AND W.G.P. SCHOUTEN ${ }^{3}$
}

${ }^{1}$ DLO-Institute of Agricultural and Environmental Engineering (IMAG-DLO), P.O. Box 43, NL-6700 AA Wageningen, The Netherlands

2 Department of Herd, Health and Reproduction, University Utrecht, P.O. Box 80151, NL-3508 TD Utrecht, The Netherlands

${ }^{3}$ Department of Animal Husbandry, Wageningen Agricultural University, P.O. Box 338, NL-6700 AA Wageningen, The Netherlands

* Corresponding author (fax: +31- 317-425670; e-mail: c.c.ketelaar-delauwere@imag.dlo.nl)

Received 1 April 1998; accepted 20 September 1998

\begin{abstract}
Forcing cows to visit the automatic milking system (AMS) regularly because it is their only way to roughage, might be questionable with regard to the cows' welfare, but leaving them free to choose whether to visit the AMS also seems to be questionable because some will pay insufficient visits to the AMS. Therefore, an alternative routing method was studied, in which the cows could move freely between the feeding and lying areas, but were stimulated to visit the AMS as only way of accessing the concentrate feeder. Two experiments were conducted, each with two treatments and 20 Holstein Friesian dairy cows. In the first treatment of experiment I, the concentrate feeder was accessible only via the AMS, and in the second treatment, it was freely accessible. In both cases a new portion of concentrate became available once every two hours. In experiment II, the concentrate feeder was available only via the AMS. A new portion of concentrate became available every two hours during the first treatment of this experiment and every four hours during the second treatment.

The results showed that allocation of concentrate in a feeder which can only be reached via the AMS is a good stimulus to attract cows to the AMS regularly, because the milking frequency increased in this situation, and the waiting time in front of the concentrate feeder and the number of aggressive interactions in this area decreased. It is better to make concentrate available once every four hours than once every two hours, because this increases concentrate intake and rest in the barn.
\end{abstract}

Keywords: automatic milking system, concentrate feeding, behaviour

\section{Introduction}

Automatic milking systems (AMS), which enable cows to be milked without human interference, are coming into commercial use (Devir et al., 1996, Rossing et al., 1997). In the present stage of development the emphasis is on 'self service' milking 
of cows. In this approach, cows are expected to visit the milking stall of the AMS voluntarily and regularly (Ipema, 1997). By creating a forced routing (also referred to as one-way routing), in which cows have to pass through the AMS to get access to the feeding area, visits can be obtained regularly (e.g. Dück, 1992; Rossing et al., 1997, Hogeveen et al., 1998). This may be supported by allocating concentrate in the AMS (Devir et al., 1997). However, forced routing is associated with decreased movement of cows through the barn (Winter et al., 1992; Metz-Stefanowska et al., 1993, Ketelaar-de Lauwere et al., 1998) as well as less lying in the cubicles (Winter \& Hillerton, 1995), less eating forage or both (Prescott et al., 1997) and increased idle standing (Winter \& Hillerton, 1995; Ketelaar-de Lauwere et al., 1998), which may be a sign of stress or discomfort (Albright, 1987). Therefore, forced routing seems questionable from the welfare point of view.

An alternative to forced cow routing is free routing in which cows can choose to visit the AMS whenever they want. However, the drawback of this method is that some cows will visit the AMS insufficiently (Ketelaar-de Lauwere et al., 1998). Concentrate allocation is a good stimulus to attract cows to the AMS, as motivation to be fed is more likely to be a sufficient stimulus than motivation to be milked (Prescott et al., 1996). If all concentrate is supplied in the AMS, cows with a large daily ration may not have sufficient time to consume it during milking; on the other hand, using the AMS for feeding without milking would reduce the capacity of the AMS (Devir et al., 1997; Ipema, 1997). Moreover, with consumption of high amounts of concentrate at one time, the probability of rumen acidosis increases (Kaufmann, 1972; Webster, 1993).

An alternative to the above methods is to locate a concentrate feeder at the exit of the AMS in such a way that it only can be reached by passing through the AMS (Prescott, 1995; Ipema, 1997). In such a situation, the forage area remains freely accessible from the lying area, and the cows' motivation for concentrate will be used to attract them to the AMS. This alternative type of cow traffic was studied in the experiments reported in this paper. In the first experiment the effect of the accessibility of the concentrate feeder was studied by comparing a treatment in which the concentrate feeder was accessible only through the AMS with one in which the concentrate feeder was freely accessible. In the second experiment the concentrate feeding regime was studied because this can affect the behaviour of the cows as well (Wierenga \& Hopster, 1991).

The aim of the study was to evaluate this type of routing in terms of the cows' visits to the AMS and the concentrate feeder, their concentrate intake, their time budget and other behaviour.

\section{Materials and methods}

\section{Animals, housing and feeding}

Two experiments (Experiments I and II) were carried out, each with a group of 20 lactating Holstein Friesian dairy cows. None of the cows in experiment I were used 

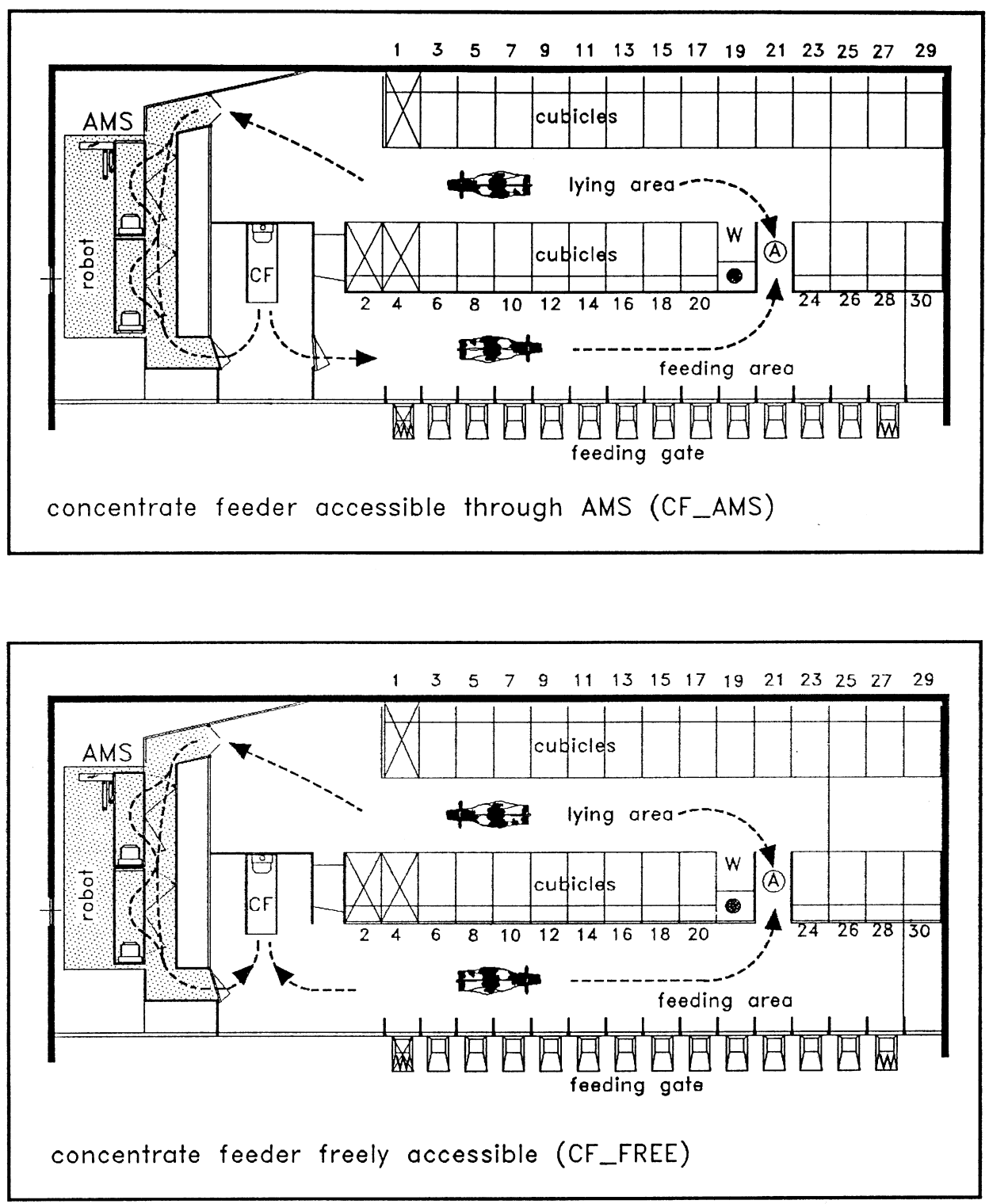

Figure 1. Plan of the cowshed during CF_AMS of experiment I and CF_AMS2 and CF_AMS4 of experiment II (above) and during CF_FREE of experiment I (below) (AMS = automatic milking system; $\mathrm{CF}=$ concentrate feeder; $\mathrm{W}=$ water; $\mathrm{A}=$ free passage between feeding and lying areas)

again in experiment II. Both experiments started with a group of 9 heifers and 11 second or higher parity cows. Days in lactation ranged from 33 to 61 for the heifers and from 34 to 150 days the second or higher parity cows in experiment I, and from 
24 to 122 days for the heifers and from 8 to 113 days for the second or higher parity cows in experiment II. The cows were kept in a section of a cubicle house with separate feeding and lying areas and a concrete slatted floor, from which manure was removed once every hour with a scraper. There were 21 cubicles available in the lying area as well as a drinking stall equipped with cow identification. In the feeding area was one drinking place and an automatic forage feeding system with 12 feeding places, each with an own feeding trough with weighing scale. The drinking place and all feeding places were equipped with cow identification. The cows could move freely between the lying area and the feeding area using a passage in the middle of the barn. They could also pass from the lying to the feeding area through an automatic milking system (AMS) (Figure 1). Forage was fed ad libitum. In experiment I, it consisted of a mixture of $60 \%$ grass silage and $40 \%$ maize silage on a dry matter basis, and in experiment II of a mixture of 50\% grass silage and 50\% maize silage on a dry matter basis. Fresh forage was provided automatically for each feeding trough separately when it was empty. Water was continuously available. In both experiments, heifers received $9 \mathrm{~kg}$ of concentrate daily and second or higher parity cows $12 \mathrm{~kg}$. Part of this ration (6 kg for heifers and $8 \mathrm{~kg}$ for second or higher parity cows) was dispensed in the automatic concentrate feeder sited in the feeding area near the exit of the AMS (Figure 1). The remaining part was fed during milking in the AMS. Heifers received $1 \mathrm{~kg}$ of concentrate per milking visit and second or higher parity cows $1.3 \mathrm{~kg}$. The AMS was always available except during cleaning between 7:30 and 8:15 a.m. and between 7:30 and 8:15 p.m. The AMS consisted of two milking stalls and a robot arm equipped with sensors for teat location. It was manufactured by Prolion in Vijfhuizen, the Netherlands. When a cow entered the AMS, the computer decided whether she should be milked. If the decision was positive, the cow received concentrate firstly, and then the cluster was attached automatically (milking visit). The minimum milking interval was $6 \mathrm{~h}$, thus cows visiting the AMS within these 6 hours were sent out of the milking stall without a concentrate reward (nonmilking visit). Twice a day, before the AMS was cleaned, cows with a milking interval of 18 hours or longer were fetched. During daytime the cowshed was illuminated by daylight and a double row of fluorescent lighting and at night by a single row of fluorescent lighting. The AMS was illuminated permanently.

\section{Experimental design}

\section{General}

Two experiments were carried out. In each experiment, two treatments, differing in the way concentrate was available in the concentrate feeder, were compared. Each treatment was applied during 3 weeks. The first week was reserved for habituation of the cows. Data were collected in the subsequent two weeks. Depending on the treatment, the daily concentrate ration of each cow was divided over 12 periods at two-hour intervals or 6 periods at four-hour intervals.

Any concentrate remaining at the end of a period was added to the next period. Concentrate left at the end of the day, was not added to the ration of the next day. 


\section{Experiment I}

In experiment I, the daily concentrate ration of each cow was divided over 12 periods of 2 hours. The portions dispensed at the two-hour intervals were $0.5 \mathrm{~kg}$ of concentrate for heifers and $0.7 \mathrm{~kg}$ for second or higher parity cows. During the first treatment of experiment I, the cows could access the concentrate feeder via the AMS (CF_AMS). This was achieved installing a one-way gate that divided the feeding area into a forage feeding area and an area with the concentrate feeder (Figure 1). The cows could move freely from the lying area to the forage area and vice versa, but they could only reach the concentrate feeder via the AMS. They could leave the concentrate area through the one-way gate to the forage area. During the second treatment of experiment I, the one-way gate was removed and the same concentrate feeder was freely accessible from all areas of the cowshed (CF_FREE; Figure 1).

\section{Experiment II}

In experiment II, the concentrate feeder was accessible only via the AMS, as during the first treatment of experiment I. The first treatment of experiment II was the same as the first treatment in experiment I (CF_AMS2). During the second treatment, the daily concentrate ration of each cow was divided over 6 periods of 4 hours (CF_AMS4). The portions dispensed at the four-hour intervals were $1.0 \mathrm{~kg}$ of concentrate for heifers and $1.3 \mathrm{~kg}$ for second or higher parity cows.

\section{Behavioural observations}

During the treatments of both experiments behaviour was monitored by video and by computer registrations for three complete 24 hour periods. Lying and standing in the cubicle and waiting in front of the concentrate feeder were recorded once every ten minutes by video. The camera for these recordings could move along a rail in the ridge of the barn. The occurrence of aggression in front of the concentrate feeder was monitored continuously by video. In addition, aggression directed towards cows in the concentrate feeder and directed towards other cows waiting in front of the concentrate feeder was distinguished. The camera for these recordings was attached to a fixed point above the area with the concentrate feeder. On-line electronic identification of each cow at several places in the barn enabled the number and duration of stays in the lying area, the forage and the concentrate area (or the entire feeding area during CF_FREE) and the AMS area to be calculated. Furthermore, the time spent at the feeding gate and the drinking trough, and the number of visits to the AMS and concentrate feeder were calculated, as well as the concentrate intake and the feed left per cow per day in the AMS and in the concentrate feeder. The types of visit to the AMS and the concentrate feeder were also monitored. AMS visits were divided into milking visits, non-milking visits and failed attachments. During milking visits, cows were milked and received concentrate in the AMS. During non-milking visits, cows were not milked and did not receive any concentrate in the AMS as their minimum milking interval of 6 hours had not yet been exceeded. During failed attach- 


\section{C.C. KETELAAR-DE LAUWERE ET AL.}

ments, cows should have been milked but were not because the milking robot failed to attach the milking cluster. In that case they received some concentrate in the AMS until it was obvious that the attachment process had failed. Visits to the concentrate feeder were divided into rewarded visits, during which the cows received concentrate, and unrewarded visits, during which they did not. AMS visits and visits to the concentrate feeder were independent of each other, i.e. an unrewarded visit to the concentrate feeder could follow a milking visit, or a non-milking visit could be followed by a rewarded visit to the concentrate feeder.

\section{Statistical analysis}

Experiments I and II were analysed separately. The Iterative Reweighted Residual Maximum Likelihood procedure (IRREML) from the Genstat 5 statistical package was used to estimate differences between treatments in both experiments (Anonymous, 1993). This algorithm estimates treatment effects and variance components in a generalised linear mixed model with both fixed and random effects (Engel and Keen, 1994). The fixed effects were the experimental situation, the lactation number and the interaction between these two factors. Because observations on the same cows were not independent, cows were incorporated into the model as random effects,. Model selection was carried out by backward elimination. The Wald statistic (VWS) was calculated to test on a 99\% probability level for the significance of fixed effects under the null hypothesis that there were no differences between treatments and/or the lactation number. This statistic has an asymptotic chi-squared distribution (Anonymous, 1993).

The behavioural variables under consideration expressed in numbers or in durations were analysed according to the generalised linear mixed model:

$$
y=\beta x+u z+\varepsilon,
$$

in which the response variable $y$ was the behaviour under consideration, $\beta$ are the fixed effects $x$ mentioned above, $u$ is the random effect of $\operatorname{cow} z$ and $\varepsilon$ is the residual error term. The variance of variables expressed in numbers was assumed to increase proportionally with $y$ and the variance of variables expressed in durations was assumed to increase proportionally with $\mathrm{y}^{2}$.

The behavioural variables lying and standing in the cubicles and the occurrence of events in front of the concentrate feeder were expressed as percentages and therefore analysed with a generalised linear mixed model assuming a binomial distribution and a logistic link function (Mc Cullagh \& Nelder, 1989). The resulting model was:

$\log (\mathrm{p} /(1-\mathrm{p}))=\beta \mathrm{x}+\mathrm{uz}+\varepsilon$,

in which $\mathrm{p}$ is the probability that the cows are seen performing the behaviour under study or the probability that a certain event in front of the concentrate feeder occurs; $\beta$ are the fixed effects $x, u$ is the random effect of $\operatorname{cow} z$ and $\varepsilon$ is the residual error term. 


\section{Results}

\section{The cows' visits to the AMS}

Table 1 gives an overview of the cows' visits to the AMS in both experiments. In experiment I, cows paid more milking and slightly more non-milking visits to the AMS during CF_AMS than during CF_FREE. In experiment II, the cows' visits to the AMS did not differ between treatments. In both experiments, all cows visited the AMS at least twice daily on average.

\section{The cows' visits to the concentrate feeder}

Table 2 gives an overview of the cows' visits to the concentrate feeder. In experiment I, cows paid more rewarded and unrewarded visits to the concentrate feeder during CF_FREE than during CF_AMS. The concentrate intake did not differ between the treatments. However, more feed left-overs were registered in CF_AMS. In experiment II, the number of visits to the concentrate feeder did not differ between the treatments, but the concentrate intake was higher and the amount of feed left-overs lower in CF_AMS4 than in CF_AMS2 . The visits to the concentrate feeder were divided equally over the 24-hour period in both treatments of the experiments.

\section{The cows' time budget}

The cows' time budget is summarised in Table 3. In experiment I, more time was spent in the forage area during CF_FREE than during CF_AMS (but the time in the forage area included the time in the concentrate area during CF_FREE). When the time in the forage area and the concentrate area were combined for CF_AMS, no dif-

Table 1. Predicted means for the cows' visits to the AMS per day in experiments I and II.

\begin{tabular}{lcccc}
\hline Experiment I & CF_AMS & CF_FREE & sed & Wald Statistic ${ }_{\mathrm{df}=1} ; P^{1}$ \\
& & & & \\
No. of AMS visits & 7.5 & 6.5 & 0.4 & $7.4 ; P=0.007$ \\
$\quad$ milking visits & 3.0 & 2.6 & 0.1 & $9.1 ; P=0.003$ \\
non-milking visits & 4.2 & 3.3 & 0.4 & $5.9 ; P=0.015$ \\
$\quad$ failed attachments & 1.6 & 2.3 & 0.5 & $1.9 ; P=0.165$ \\
Total time in AMS (min) & 38.1 & 33.7 & 3.6 & $1.6 ; P=0.213$ \\
Avg. time in AMS (min) & 5.9 & 6.2 & 0.6 & $0.2 ; P=0.626$ \\
& & & & \\
Experiment II & CF_AMS2 & CF_AMS4 & sed & Wald Statistic \\
& & & & \\
No. of AMS visits & 7.3 & 7.0 & 0.4 & $0.4 ; P=0.529$ \\
$\quad$ milking visits & 2.7 & 2.8 & 0.1 & $1.3 ; P=0.253$ \\
non-milking visits & 4.2 & 4.0 & 0.3 & $0.4 ; P=0.525$ \\
failed attachments & 1.5 & 1.8 & 0.5 & $0.4 ; P=0.532$ \\
Total time in AMS (min) & 39.7 & 41.6 & 3.4 & $0.3 ; P=0.578$ \\
Avg. time in AMS (min) & 6.3 & 6.6 & 0.6 & $0.4 ; P=0.508$ \\
\hline
\end{tabular}

\footnotetext{
1 differences between treatments are considered to be significant when $P<0.01$.
} 
C.C. KETELAAR-DE LAUWERE ET AL.

Table 2. Predicted means for the cows' visits to the concentrate feeder per day in experiments I and II.

\begin{tabular}{lcccc}
\hline Experiment I & CF_AMS & CF_FREE & sed & Wald Statistic ${ }_{\mathrm{df}=1} ; P^{1}$ \\
Visits to concentrate feeder & 7.7 & 11.9 & 0.4 & $122.4 ; P=0.000$ \\
$\quad$ rewarded visits & 5.8 & 7.8 & 0.3 & $52.5 ; P=0.000$ \\
$\quad$ unrewarded visits & 2.3 & 4.0 & 0.3 & $32.1 ; P=0.000$ \\
Concentrate intake (kg) & 6.3 & 6.6 & 0.2 & $2.6 ; P=0.104$ \\
Feed left-overs (\%) & $12.8(3.3)$ & $6.9(3.2)$ & $*$ & $7.8 ; P=0.005$ \\
& & & & \\
Experiment II & CF_AMS2 & CF_AMS4 & sed & Wald Statistic; $P^{1}$ \\
& & & & \\
Visits to concentrate feeder & 7.3 & 6.9 & 0.4 & $0.9 ; P=0.345$ \\
$\quad$ rewarded visits & 5.2 & 4.7 & 0.2 & $5.0 ; P=0.025$ \\
$\quad$ unrewarded visits & 2.4 & 2.7 & 0.3 & $1.2 ; P=0.284$ \\
Concentrate intake (kg) & 5.6 & 6.4 & 0.2 & $13.7 ; P=0.000$ \\
Feed left-overs (\%) & $16.5(4.9)$ & $8.9(4.5)$ & $*$ & $8.9 ; P=0.003$ \\
\hline
\end{tabular}

1 differences between treatments are considered to be significant when $P<0.01$;

* no reliable estimation of sed can be made when using logistic models; therefore, SE has been given in brackets, as indication of deviation.

ference in the time spent in the feeding area was found between the treatments of experiment I (Table 3). In addition, an interaction was found between treatment and lactation number. Second or higher parity cows spent more time at the feeding gate during $\mathrm{CF}_{-} \mathrm{AMS}$ than during CF_FREE. No difference between treatments was found for heifers.

In experiment II, the cows spent more time lying in the cubicles in CF_AMS4 than in CF_AMS2. Besides this, the average duration of feeding periods was longer and the total time spent in the concentrate area was lower during CF_AMS4 than during CF_AMS2.

\section{Events in front of the concentrate feeder}

Table 4 summarises events in front of the concentrate feeder. During CF_FREE (experiment I), cows waited longer and more aggressive interactions were seen in front of the concentrate feeder than during CF_AMS. Besides this, during CF_FREE, cows more often left the AMS without visiting the concentrate feeder and the concentrate feeder was more often occupied when they wanted to visit it. In experiment II, cows waited in front of the concentrate feeder longer and the concentrate feeder was more often occupied when cows wanted to visit it during CF_AMS2 than during CF_AMS4. Aggression directed towards the cow in the concentrate feeder was seen more frequently during CF_AMS4.

\section{Differences between heifers and second or higher parity cows}

In both experiments, differences between heifers and second or higher parity cows were found for several aspects of the cows' behaviour described above. These differ- 
Table 3. Time budget of cows (per day) in experiments I and II (predicted means).

\begin{tabular}{|c|c|c|c|c|}
\hline Experiment I & CF_AMS & CF_FREE & sed & Wald Statistic $_{\mathrm{df}=1} ; P^{1}$ \\
\hline Time in lying area (min) & 983.5 & 967.5 & 18.9 & $0.7 ; P=0.394$ \\
\hline No. of stays in lying area & 12.9 & 12.3 & 0.4 & $2.9 ; P=0.090$ \\
\hline Lying in cubicle (min) & $612.9(31.6)$ & $628.9(31.7)$ & $*$ & $0.9 ; P=0.356$ \\
\hline no. of lying periods & 6.7 & 6.9 & 0.3 & $0.5 ; P=0.465$ \\
\hline av. duration of lying periods ( $\mathrm{min}$ ) & 97.5 & 96.1 & 4.9 & $0.1 ; P=0.779$ \\
\hline Standing in cubicle (min) & $200.9(32.3)$ & $210.4(32.7)$ & $*$ & $0.6 ; P=0.455$ \\
\hline Time in forage area $(\mathrm{min})^{2}$ & 347.2 & 430.7 & 15.7 & $28.5 ; P=0.000$ \\
\hline No. of stays in forage area & 12.3 & 11.9 & 0.4 & $1.4 ; P=0.236$ \\
\hline Time at feeding gate $(\mathrm{min})^{3}$ & & & & $11.7 ; P=0.001$ \\
\hline heifers & 163.5 & 180.8 & 10.1 & not significant \\
\hline 2nd. or higher parity cows & 206.8 & 175.2 & 10.2 & significant \\
\hline no. of feeding periods & 9.9 & 9.8 & 0.3 & $0.1 ; P=0.784$ \\
\hline av. duration of feeding periods (min) & 19.8 & 19.3 & 1.1 & $0.2 ; P=0.691$ \\
\hline Time in AMS (min) & 38.1 & 33.7 & 3.6 & $1.6 ; P=0.213$ \\
\hline Time in concentrate area $(\min )^{4}$ & 59.8 & - & - & - \\
\hline Time in feeding area (min) & 410.3 & 429.7 & 15.7 & $1.5 ; P=0.214$ \\
\hline Experiment II & CF_AMS2 & CF_AMS4 & sed & Wald Statistic $_{\mathrm{df}=1} ; P^{1}$ \\
\hline Time in lying area (min) & 969.5 & 993.2 & 19.8 & $1.4 ; P=0.231$ \\
\hline No. of stays in lying area & 11.9 & 11.2 & 0.4 & $2.8 ; P=0.096$ \\
\hline Lying in cubicle (min) & $601.8(37.4)$ & $661.5(37.6)$ & $*$ & $7.6 ; P=0.006$ \\
\hline no. of lying periods & 6.2 & 6.8 & 0.3 & $5.2 ; P=0.023$ \\
\hline av. duration of lying periods ( $\mathrm{min}$ ) & 99.6 & 100.0 & 5.0 & $0.01 ; P=0.923$ \\
\hline Standing in cubicle (min) & $195.1(38.2)$ & $176.8(37.2)$ & $*$ & $2.3 ; P=0.129$ \\
\hline Time in forage area (min) & 333.0 & 337.0 & 13.9 & $0.1 ; P=0.772$ \\
\hline No. of stays in forage area & 11.6 & 10.8 & 0.4 & $3.2 ; P=0.072$ \\
\hline Time at feeding gate (min) & 181.8 & 189.2 & 5.1 & $2.1 ; P=0.151$ \\
\hline no. of feeding periods & 9.3 & 8.6 & 0.3 & $4.6 ; P=0.032$ \\
\hline av. duration of feeding periods (min) & 20.3 & 22.5 & 0.7 & $10.0 ; P=0.002$ \\
\hline Time in AMS (min) & 39.7 & 41.6 & 3.4 & $0.3 ; P=0.578$ \\
\hline Time in concentrate area $(\mathrm{min})$ & 74.4 & 62.9 & 3.9 & $8.7 ; P=0.003$ \\
\hline
\end{tabular}

1 differences between treatments are considered to be significant when $P<0.01$;

2 includes the concentrate area in CF_FREE;

3 predicted means are mentioned separately for heifers and second or higher parity cows when a significant interaction was found between treatment and lactation number;

4 no separate concentrate area in CF_FREE;

* no reliable estimation of sed can be made when using logistic models; therefore, SE has been given in brackets as indication of deviation.

ences are summarised in Table 5. In experiment I, the total number of AMS visits, the number of non-milking visits, the total number of visits to the concentrate feeder, the number of unrewarded visits to the concentrate feeder, the number of stays in the lying and forage area, the number of feeding periods and the percentage of times that the cows did not visit the concentrate feeder when leaving the AMS was higher for heifers than for second or higher parity cows. Besides this, in experiment I, the average time spent in the AMS per visit, the average duration of feeding periods and 
Table 4. Daily events in front of the concentrate feeder (CF) in experiments I and II (predicted means; $\mathrm{SE}$ in brackets).

\begin{tabular}{|c|c|c|c|}
\hline Experiment I & CF_AMS & CF_FREE & Wald Statistic $_{\mathrm{df}=1} ; P^{1}$ \\
\hline Waiting in front of CF (min) & $24.8(14.5)$ & $53.1(17.6)$ & $46.0 ; P=0.000$ \\
\hline $\begin{array}{l}\text { No. of aggressive interactions in front } \\
\text { of } \mathrm{CF}\end{array}$ & $2.1(0.3)$ & $4.2(0.3)$ & $\begin{array}{l}23.5 ; P=0.000 \\
\text { sed }=0.4\end{array}$ \\
\hline$\%$ leaving AMS without $\mathrm{CF}$ visit & $3.5(2.8)$ & $7.1(2.2)$ & $7.6 ; P=0.006$ \\
\hline$\% \mathrm{CF}$ occupied related to no. of CF visits & $53.5(2.3)$ & $65.3(1.7)$ & $18.3 ; P=0.000$ \\
\hline $\begin{array}{l}\text { Occurrence of aggression (in \%) } \\
\text { directed towards cow in CF related } \\
\text { to no. of times that CF was occupied }\end{array}$ & $91.8(4.4)$ & $91.0(3.5)$ & $0.2 ; P=0.690$ \\
\hline Experiment II & CF_AMS2 & CF_AMS4 & Wald Statistic; $P^{1}$ \\
\hline Waiting in front of CF (min) & $34.4(14.8)$ & $22.3(13.5)$ & $11.7 ; P=0.001$ \\
\hline $\begin{array}{l}\text { No. of aggressive interactions in front } \\
\text { of } \mathrm{CF}\end{array}$ & $1.8(0.2)$ & $1.5(0.3)$ & $\begin{array}{l}0.9 ; P=0.349 \\
\text { sed }=0.3\end{array}$ \\
\hline$\%$ leaving AMS without $\mathrm{CF}$ visit & $4.5(2.9)$ & $3.8(3.2)$ & $0.3 ; P=0.603$ \\
\hline$\%$ CF occupied related to no. of CF visits & $59.3(2.2)$ & $43.5(2.4)$ & $25.9 ; P=0.000$ \\
\hline $\begin{array}{l}\text { Occurrence of aggression (in \%) } \\
\text { directed towards cow in CF related to } \\
\text { no. of times that CF was occupied }\end{array}$ & $39.0(6.5)$ & $57.7(6.9)$ & $15.1 ; P=0.000$ \\
\hline
\end{tabular}

1 differences between treatments are considered to be significant when $P<0.01$.

the time spent at the feeding gate during CF_AMS was lower for heifers than for second or higher parity cows. In experiment II, heifers spent more time on average in the AMS per visit than second or higher parity cows. In both experiments heifers ate less concentrate in the concentrate feeder than second or higher parity cows.

\section{Discussion}

The cows' visits to the AMS and the concentrate feeder

Allocating concentrate in a concentrate feeder that can be reached only via the AMS, appeared to be a good stimulus to attract cows to the AMS in this study. The total number of visits to the AMS was sufficient, with an estimated average daily milking frequency of almost 3 (including failed attachments). This is comparable with other findings in free and forced routing situations (Devir, 1995). A daily milking frequency of 3 seems to be optimal, as Ipema \& Benders (1992) have found that raising the daily milking frequency from 2 to 3 can boost milk production by $14 \%$, and raising it from 2 to 4 boost it by $15 \%$ but causes more erosion and eruption of the teat ends. Rossing et al. (1985) and Rabold (1986) report a daily milking frequency of 4 when cows are milked in a concentrate feeder, but in both cases the criterion for milking was a minimum interval of 3 hours (additionally, in the experiment of Rossing et al., the expected milk yield had to be higher than $3.5 \mathrm{~kg}$ ). 
Table 5. Differences between heifers and 2nd. or higher parity cows in experiments I and II (predicted means).

\begin{tabular}{|c|c|c|c|c|}
\hline Experiment I & Heifers & $\begin{array}{l}\text { 2nd. or higher } \\
\text { parity cows }\end{array}$ & sed & Wald Statistic $_{\mathrm{df}=1} ; P^{1}$ \\
\hline No. of AMS visits & 9.0 & 4.9 & 1.0 & $16.3 ; P=0.000$ \\
\hline Non-milking visits & 5.0 & 2.5 & 0.7 & $13.7 ; P=0.000$ \\
\hline Avg. time in AMS (min) & 4.7 & 7.4 & 1.0 & $7.4 ; P=0.007$ \\
\hline Visits to concentrate feeder & 11.3 & 8.0 & 1.0 & $11.4 ; P=0.001$ \\
\hline Unrewarded visits to $\mathrm{CF}^{2}$ & 4.1 & 2.2 & 0.5 & $16.3 ; P=0.000$ \\
\hline No. of stays in lying area & 14.3 & 10.9 & 1.0 & $11.4 ; P=0.001$ \\
\hline No. of stays in forage area & 13.7 & 10.5 & 1.0 & $10.4 ; P=0.001$ \\
\hline No. of feeding periods & 10.8 & 8.8 & 0.8 & $7.6 ; P=0.006$ \\
\hline Avg. duration of feeding periods (min) & 16.3 & 22.8 & 1.8 & $12.8 ; P=0.000$ \\
\hline Time at feeding gate $(\mathrm{min})^{3}$ & & & & $11.7 ; P=0.001$ \\
\hline CF_AMS & 163.5 & 206.8 & 11.5 & significant \\
\hline CF_FREE & 180.8 & 175.2 & 11.2 & not significant \\
\hline $\begin{array}{l}\% \text { leaving without } \mathrm{CF} \text { visit related to } \\
\text { no. of } \mathrm{CF} \text { approaches }{ }^{2}\end{array}$ & $8.1(2.8)$ & $3.1(2.5)$ & $*$ & $13.4 ; P=0.000$ \\
\hline Concentrate intake in $\mathrm{CF}(\mathrm{kg})$ & 5.7 & 7.2 & 0.2 & $46.2 ; P=0.000$ \\
\hline \multicolumn{5}{|l|}{ Experiment II } \\
\hline Avg. time in AMS (min) & 7.5 & 5.5 & 0.7 & $7.9 ; P=0.005$ \\
\hline Concentrate intake in $\mathrm{CF}(\mathrm{kg})$ & 5.0 & 7.1 & 0.4 & $30.2 ; P=0.000$ \\
\hline \multicolumn{5}{|c|}{$\begin{array}{l}{ }^{1} \text { differences between treatments are considered to be significant when } P<0.01 \text {; } \\
2 \mathrm{CF}=\text { concentrate feeder; } \\
{ }^{3} \text { predicted means are mentioned separately for different treatments when a significant interaction was } \\
\text { found between treatment and lactation number; } \\
\text { * no reliable estimation of sed can be made when using logistic models; therefore, SE in brackets as in- } \\
\text { dication of deviation. }\end{array}$} \\
\hline
\end{tabular}

When the concentrate feeder was freely accessible from all areas of the cowshed, the number of AMS visits decreased. Similar results are reported by Ketelaar-de Lauwere et al. (1993) for visits to a simulated AMS. It is striking that the number of visits to the concentrate feeder during CF_FREE is similar to the findings of other authors ( Andreae \& Smidt, 1983; Wierenga \& Hopster, 1991), but that visits during CF_AMS were lower. Grimm et al. (1980) report that the number of visits to a concentrate feeder fell from 15.3 to 5.4 when cows were also milked in it. Rossing et al. (1985) and Rabold (1986) report average visiting frequencies of 5.4 and 5.9 respectively when cows could also be milked in a concentrate feeder. It seems likely that, milking in a concentrate feeder or in front of it, deters cows from visiting the feeder. A possible explanation for this might be the cows' reluctance to 'isolate' themselves from the herd (Hurnik, 1994), their dislike of the milking procedure (Royle et al., 1992), or of the uncertainty (Wiepkema \& Koolhaas, 1993) of being milked or their dislike of the milking device itself (Hurnik, 1994). The 'extra' visits to the concentrate feeder when it was freely accessible, increased waiting times and aggressive interactions in front of it. More cow traffic in the cubicle house is indeed likely to re- 
sult in more social confrontations (Wierenga \& Hopster, 1991). When the concentrate feeder was accessible only via the AMS and concentrate became available every four hours instead of every two hours, the number of rewarded visits to the concentrate feeder decreased slightly, but the concentrate intake was higher and less feed was left. In that case, the cows also had shorter waiting times in front of the concentrate feeder and it was less often occupied when they approached it. Aggression directed towards the cow in the concentrate feeder has been reported to be $60 \%$ and 67\% (Metz-Stefanowska \& Spahr (1989) and Hettinga \& Van Der Burg (1989) respectively). These levels varied from $39 \%$ to $92 \%$ in the present experiments. It is not clear why the level of aggression directed to other cows in the feeder was higher in experiment I than in experiment II. This might be an observer's effect. In experiment II, though it was striking that aggression directed towards cows in the feeder was seen more frequently when concentrate became available every four hours. Probably, cows were more eager to visit the concentrate feeder and therefore more aggressive in this case. Metz (1983) and Olofsson (1994) report more aggression when food is restricted in either time or space. In the present study, there was less opportunity to obtain concentrate when this became available every four hours. This may have resulted in the 'increased level of competition'.

\section{The cows' time budget}

Cows should have enough time to rest and eat because these behavioural activities are important for maintenance of homeostasis (Webster, 1993) and successful adaptation to the environment (Wierenga, 1991). Metz (1985) described lying as an important behaviour for which cows demonstrate a strong motivation. In experiment I, no important differences were found in the cows' time budget. In experiment II, lying times were longer and the time spent in the concentrate area was shorter when concentrate became available every four hours instead of every two hours. This promoted rest in the barn. Furthermore, when concentrate became available every two hours, the average duration of feeding periods was shorter and there were slightly more feeding periods, indicating that cows probably interrupted their activities more often in this case. Therefore, allocating concentrate every four hours instead of every two hours may be preferable. Research has shown that cows easily adapt to different concentrate feeding routines (Wierenga \& Hopster, 1991; Livshin et al., 1994) and that this might affect the timing and duration of general activities such as lying and eating forage (Wierenga \& Hopster, 1991, Morita et al., 1996).

\section{Heifers and second or higher parity cows}

All the statistically significant differences found between heifers and second or higher parity cows in this study show that heifers were more active (or restless) than second or higher parity cows. This has been reported earlier for behaviour in general (Baehr, 1984; Kempkens \& Boxberger, 1987), for visits to an AMS (Devir et al., 1995; Prescott, 1995, Hogeveen et al., 1998), and for visits to a concentrate feeder (Collis, 1980). 


\section{Evaluation of the experiment}

The cows' visits to the AMS and the concentrate feeder and their time budget were quite similar during similar treatments ( $\mathrm{CF} \_\mathrm{AMS}$ of experiment I and CF_AMS2 of experiment II). Therefore, $\mathrm{CF}_{-} \mathrm{AMS}$ and $\mathrm{CF}_{-} \mathrm{AMS} 2$ seem to be a reliable basis for studying the effects of the accessibility of the concentrate feeder (experiment I) and the feeding regime (experiment II). It would, nevertheless, have been better if more replications of all treatments could have been studied (Mead, 1988). Unfortunately, the cost of experiments with fully automatically milked cows precludes this. Despite these restrictions, the results presented, provide information that might be useful for installing fully automatic milking systems on commercial farms so that cows benefit by not being forced to follow a certain route, and the farmer benefits because cows use the AMS adequately. However, it should be taken into account that the cows of the presented experiment were all in the first part of their lactation, and, therefore, received a high daily ration of concentrate. Further research to study the effect of the level of concentrate on the cows' visits to the AMS and their behaviour if the concentrate feeder is accessible only through the AMS could be useful. In such an experiment, the level of concentrate could be varied per group, but also per cow, as both versions may have different consequences for the cows' visits to the AMS and their behaviour. In addition, it should be taken into account that the experiments were carried out with 20 cows only. This means that the capacity of the AMS was not fully utilised. Therefore, it could be useful to study the presented type of cow routing with more cows in future research as well.

\section{Conclusions}

Allocation of concentrate in a concentrate feeder which can only be reached by passing through the AMS appeared to be a good stimulus to attract cows to the AMS at regular intervals as the cows were milked sufficiently often. It appeared to be more favourable to make concentrate available every four hours rather than every two hours, because there was more rest in the barn, the concentrate intake was higher and less feed was left over in that case.

A critical observation should, however, be added: the cows that had to pass through the AMS instead of having free access to the concentrate feeder, paid fewer visits to this feeder, and more feed was left. Using this way of concentrate allocation to attract cows to the AMS, therefore, might be a good tool, but remains a compromise in terms of cows' voluntary feed intake.

\section{Acknowledgements}

Dr. M.M.W.B. Hendriks of the Centre for Biometry in Wageningen and Dr. C.E. Van 't Klooster of the DLO-Institute of Agricultural and Environmental Engineering (IMAG-DLO) in Wageningen are thanked for their useful comments on earlier drafts 
of this paper. The students mrs. M. Van Der Made and N. Van Der Waart are thanked for their contribution in the data collection and analysis.

\section{References}

Albright, J.L., 1987. Dairy animal welfare: current and needed research. Journal of Dairy Science 70: 2711-2731.

Andreae, U. \& D. Smidt, 1983. Tagesrhythmik, Sozialverhalten und Ruheverhalten von Milchkühen bei kontinuierlicher automatischer Kraftfutterversorgung. Landbauforschung Völkenrode 33: 208-218.

Anonymous, 1993. Genstat 5 Reference Manual; Version 3. Clarendon Press, Oxford, 796 pp.

Baehr, J., 1984. Verhalten von Milchkühen in Laufställen. KTBL-Schrift 293. Kuratorium für Technik und Bauwesen (KTBL), Darmstadt, $151 \mathrm{pp}$.

Collis, K.A., 1980. The effect of an automatic feed dispenser on the behaviour of lactating dairy cows. Applied Animal Ethology 6: 139-147.

Devir, S., 1995. The dairy control and management system in the robotic milking farm. PhD Thesis, Wageningen Agricultural University, Wageningen, $95 \mathrm{pp}$.

Devir, S., C.C. Ketelaar-de Lauwere \& J.P.T.M. Noordhuizen, 1995. The milking robot dairy farm management: operational performance characteristics and consequences. In: S. Devir, The dairy control and management system in the robotic milking farm. PhD-Thesis, Wageningen Agricultural University, Wageningen, pp. 43-71.

Devir, S., H. Hogeveen, P.H. Hogewerf, A.H. Ipema, C.C. Ketelaar-de Lauwere, W. Rossing, A.C. Smits \& J. Stefanowska, 1996. Design and implementation of a system for automatic milking and feeding. Canadian Agricultural Engineering 38: 107-113.

Devir, S., E. Maltz \& J.H.M. Metz, 1997. Strategic management and planning and implementation at the milking robot dairy farm. Computers and Electronics in Agriculture 17: 95-110.

Dück, M., 1992. Evolution of Düvelsdorf milking robot. In: A.H. Ipema, Lippus, A.C., Metz, J.H.M. \& Rossing, W. (Eds.), Prospects for automatic milking. Pudoc Scientific Publishers, Wageningen, pp. 49-54.

Engel, B. \& A. Keen, 1994. A simple approach for the analysis of generalized linear mixed models. Statistica Neerlandica 48: 1-22.

Grimm, H., H. Kraus, B. Nuber, \& M. Vogel, 1980. Verhalten von Kühen bei Transponderfütterung mit mehrmaligem, unregelmäßigem Milchentzug am Kraftfutterautomaten. KTBL-Schrift 254. Kuratorium für Technik und Bauwesen (KTBL), Darmstadt, pp. 133-136.

Hettinga, T.E.M. \& A. Van Der Burg, 1989. De relatie tussen doseersnelheid, capaciteit, restvoer en agressie, bij spaar- en periodensysteem (In Dutch with English summary). In: H.K. Wierenga \& A. van der Burg (Eds.), Concentrate intake and behaviour of dairy cows with programmed concentrate distribution. Pudoc Scientific Publishers, Wageningen, pp. 81-87.

Hogeveen, H., A.J.H. van Lent \& C.J. Jagtenberg, 1998. Free and One-way Cow Traffic in Combination with Automatic Milking. In: J.P. Chastain (Ed.), Proceedings of the Fourth International Dairy Housing Conference, American Society of Agricultural Engineers (ASAE), Michigan, pp. 80-87.

Hurnik, J.F., 1994. Ethological approach to the management of dairy parlours. In: R. Bucklin (Ed.), Dairy systems for the 21st century. American Society of Agricultural Engineers (ASAE), Michigan pp. 43-48.

Ipema, A.H., 1997. Integration of robotic milking in dairy housing systems - Review of cow traffic and milking capacity aspects. Computers and Electronics in Agriculture 17: 79-94.

Ipema, A.H. \& E. Benders, 1992. Production, duration of machine-milking and teat quality of dairy cows milked 2, 3 or 4 times daily with variable intervals. In: A.H. Ipema, A.C. Lippus, J.H.M. Metz \& W. Rossing (Eds.), Prospects for automatic milking. Pudoc Scientific Publishers, Wageningen, pp. 244-252.

Kaufmann, W., 1972. Verdauungsphysiologische Messungen zur 'biologischen Fütterungstechnik' bei Milchkühen. Kieler Milchwirtschaftliche Forschungsberichte, 24: 139-155.

Kempkens, K. \& J. Boxberger, 1987. Locomotion of cattle in loose housing systems. In: H.K. Wierenga \& J.D. Peterse (Eds.), Cattle housing systems, lameness and behaviour. Martinus Nijhoff, London, pp. $107-118$. 
Ketelaar-de Lauwere, C.C., E. Benders \& P.J.M. Huijsmans, 1993. The response of cows to concentrate feeding in the cowshed being made dependent on that in the automatic milking system - the influence of different cowshed layouts (In Dutch; with English summary), Report 93-18. DLO-Institute of Agricultural and Environmental Engineering (IMAG-DLO), Wageningen, 23 pp.

Ketelaar-de Lauwere, C.C., M.M.W.B. Hendriks, J.H.M. Metz \& W.G.P. Schouten, 1998. Behaviour of dairy cows under free or forced cow traffic in a simulated automatic milking system environment. $A p$ plied Animal Behaviour Science 56: 13-28.

Livshin, N., E. Maltz \& Y. Edan, 1994. Regulating dairy cows' visits to self feeders by changing the feeding routine. In: R. Bucklin (Ed.), Dairy systems for the 21st century. American Society of Agricultural Engineers (ASAE), Michigan, pp. 496-502.

McCullagh, P. \& J.A. Nelder, 1989. Generalized Linear Models, 2nd. Ed., Chapman and Hall, London, $511 \mathrm{pp}$.

Mead, R., 1988. The design of experiments - statistical principles for practical application. Cambridge University Press, Cambridge, 620 pp.

Metz. J.H.M., 1983. Food competition in cattle. In S.H. Baxter, M.R. Baxter \& J.A.C. MacCormack (Eds.), Farm animal housing and welfare. Martinus Nijhoff Publishers, Boston, pp. 164-170.

Metz, J.H.M., 1985. The reaction of cows to a short-term deprivation of lying. Applied Animal Behaviour Science 13: 301-307.

Metz-Stefanowska, J. \& S.L. Spahr, 1989. Behavioural observations on a group of cows using a dual computer-controlled concentrates dispenser. Research Report 89-1, DLO-Institute for Agricultural and Environmental Engineering (IMAG-DLO), Wageningen, 23 pp.

Metz-Stefanowska, J., A.H. Ipema, C.C. Ketelaar-de Lauwere \& E. Benders, 1993. Feeding and drinking strategy of dairy cows after the introduction of one-way traffic into the loose housing system in the context of automatic milking. In: E. Collins \& C. Boon (Eds.), International Livestock Environment IV. ASAE publication 03-93. American Society of Agricultural Engineers (ASAE), Michigan, USA, pp. 319-329.

Morita, S., S. Devir, C.C. Ketelaar-de Lauwere, A.C. Smits, H. Hogeveen \& J.H.M. Metz, 1996. Effects of concentrate intake on subsequent roughage intake and eating behavior of cows in an automatic milking system. Journal of Dairy Science 79: 1572-1580.

Olofsson, J., 1994. Competition for feed in loose housing sytems. In: R. Bucklin (ed.), Dairy systems for the 21st century. American Society of Agricultural Engineers (ASAE), Michigan, pp. 825-828.

Prescott, N.B., 1995. Dairy cow behaviour and automatic milking, PhD Thesis, University of Bristol, Bristol, 290 pp.

Prescott, N.B., T.T.F. Mottram \& A.J.F. Webster, 1996. Reinforcing properties of milking vs. feeding for high and low yielding dairy cows in a y-maze and an automatic milking system. In: I.J.H. Duncan, T.M. Widowski \& D.B. Haley (Eds.), Proceedings of the 30th International Congress of the International Society for Applied Ethology (ISAE).Centre for the Study of Animal Welfare (CSAW), Guelph, p. 129.

Prescott, N.B., T.T. Mottram \& A.J. Webster, 1997. Experiments studying the interaction between dairy cow behaviour and automatic milking. In: R.W. Bottcher \& S.J. Hoff (Eds.), Livestock Environment V, Vol. II. American Society of Agricultural Engineers (ASAE), Michigan, pp. 1090-1097.

Rabold, K., 1986. Vollautomatisches Melken - Erste Ergebnisse aus Tierverhaltens- und physiologischen Untersuchungen - Landtechnik 41: 224-226.

Rossing, W., A.H. Ipema \& P.F. Veltman, 1985. The feasibility of milking in a feeding box. Research Report 85-2, DLO-Institute for Agricultural and Environmental Engineering (IMAG-DLO), Wageningen, 39 pp.

Rossing, W., P.H. Hogewerf, A.H. Ipema, C.C. Ketelaar-de Lauwere \& C.J.A.M. de Koning, 1997. Robotic milking in dairy farming. Netherlands Journal of Agricultural Science 45: 15-31.

Royle, C., P.C. Garnsworthy, A.J. McArthur, \& T.B. Mephan, 1992. Effects of frequent milking on heart rate and other physiological variables in dairy cows. In: A.H. Ipema, Lippus, A.C., Metz, J.H.M. \& W. Rossing (Eds.), Prospects for automatic milking. Pudoc Scientific Publishers, Wageningen, pp. 237-243.

Webster, J., 1993. Understanding the dairy cow. 2nd. edition, Blackwell Science, Oxford, $374 \mathrm{pp}$.

Wiepkema, P.R. \& J.M. Koolhaas, 1993. Stress and animal welfare. Animal Welfare 2: 195-218.

Wierenga, H.K., 1991. Behaviour of dairy cows under modern housing and management. PhD Thesis, Wageningen Agricultural University, Wageningen, 173 pp. 


\section{C.C. KETELAAR-DE LAUWERE ET AL.}

Wierenga, H.K. \& H. Hopster, 1991. Behaviour of dairy cows when fed concentrates with an automatic concentrates feeding system. Applied Animal Behaviour Science 30: 223-246.

Winter, A., R.M. Teverson \& J.E. Hillerton, 1992. The effect of increased milking frequency and automated milking systems on the behaviour of the dairy cow. In: A.H. Ipema, A.C. Lippus, J.H.M. Metz \& W. Rossing (Eds.), Prospects for automatic milking. Pudoc Scientific Publishers, Wageningen, pp. 261-269.

Winter, A. \& J.E. Hillerton, 1995. Behaviour associated with feeding and milking of early lactation cows housed in an experimental automatic milking system. Applied Animal Behaviour Science 46: $1-15$. 